\title{
S. P. Gill: Tacit engagement: beyond interaction
}

\section{Springer, 2015}

\author{
Kathleen Richardson ${ }^{1}$
}

Published online: 16 November 2016

(C) Springer-Verlag London 2016
Satinder Gill's book, Tacit Engagement: Beyond Interaction (2015 Springer) offers an insightful and important critique of tacit engagement moving beyond a mechanical model of 'interaction' as an information exchange system into one that can hold onto the fullness of dialogue-openended, not instrumental, and spontaneous interaction. To grace this special issue on Buber a review of this book is apt. Gill draws on Buber's I and Thou throughout her book to illustrate the unique approach of Buber and his commitment to relationality and dialogue. For Buber, I-It relations were characterized by experience of the othertaking from them something that is needed. He contrasted this with I-thou-a meeting with, fully in the moment, a way of recognizing rather than taking. It is true that Buber never believed the I-Thou could be sustained, and he embedded in his concept of I-thou a temporary feature, suggesting that as soon as one tries to grasp the I-Thou, it becomes the I-It, evaluative, rational, precise. With that said, as this special issue bears testament that the Thou offers something beyond the I-It-Gill invites us to consider these possible journeys.

Gill takes us on an autobiographical journey through her academic careers to creative effect, situating her academic discourse in embodied relational contexts, meeting and encounters with others, problems and concerns discussed and forgotten and returned to again at different times with different technologies. A central theme in the book is interface, 'the world we now inhabit is filled with computer-

Kathleen Richardson

kathleen.richardson@dmu.ac.uk

1 Centre for Computing and Social Responsibility, De Montfort University, Leicester LE1 9BH, UK based technologies that interface our relations with each other, our thinking through problems, making decisions, and making consumer choices. The interface, that inbetweeness, mediates humans with one another or with machines' she writes. The interface as both metaphor and physical structure is apt. An interface is a thing in itself, but it mediates, and is inbetween, and Gill invites us to reflect on the models of the human who is characterized as using, as well as being on either side of, this interface. Rather than dialogue information is the model supreme. Information fails in its model to truly appreciate the complexity of human relationality or the tacit engagements involved. The meaning of tacit is key here. Gill situates her narrative in Polayani's The Tacit Dimension [1966/2009], tacit- 'to know more than we can tell'. Polyani supported those attempts to bring bodies and cognition together; he writes 'the distinction between subject and object is blurred in my body' (p. 27). Drawing on the phenomenological and dialogical philosophers, Gill outlines the contribution of thinkers including Heidegger [1889-1976], Gadamer [1900-2002] and Wittgenstein [1889-1951]. Gill adds wonderful complexity to her discussion of computer-mediated interaction by drawing on human-human mediated narrative though dialogical phenomenological discourses. Before machines, people speculated about these issues in relation to people. The books end on an optimistic note, that if technologists, innovators, and AI researchers pay attention to tacit engagement this could enable the technology to flourish-I could not agree with her more. A highly recommended read. 